\title{
Influence of Monitoring Tools on Project Performance in Kenyan State Corporations
}

\author{
Muchelule Yusuf Wanjala \\ Prof. Mike Amuhaya Iravo \\ Prof. Romanus Odhiambo \\ Dr. Noor Ismail Shalle
}

Jomo Kenyatta University of Agriculture and Technology, Kenya

doi: 10.19044/esj.2017.v13n19p354 URL:http://dx.doi.org/10.19044/esj.2017.v13n19p354

\begin{abstract}
The main objective of this study was to investigate the influence of monitoring tools on project performance of Kenyan State Corporations. Simple random sampling was used to select 65 state corporations that constituted the sample size. Data were collected from the sample size using questionnaires with both open and closed questions and they were administered by the researcher through a drop and pick technique. The collected data was analyzed using descriptive and inferential statistics as well as qualitative methods. The relationships between variables were determined using Pearson correlation and t-test. Assessments of normality were done by Shapiro-Wilk test while multicollinearity was detected by use of variation inflation factor (VIF). The study revealed that monitoring tools had no significant effect on project performance in Kenyan State Corporations $\left(\beta_{2}=0.073, \mathrm{p}>0.05\right)$. there is also a possibility that the monitoring tools were unable to map out the needed steps to attain the desired project results.
\end{abstract}

Keywords: project baselines, project checklists, project metrics, Project management plan, project Reports

\section{INTRODUCTION}

Monitoring is defined as the continuous routine tracking of the key elements of project implementation performance that is: inputs (resources, equipment) activities and outputs, through recordkeeping and regular reporting (McCoy, Ngari \& Krumpe, 2005). It is also the tracking the planned implementation against the actual implementation, to able to report on how the project is progressing and if there is a need for corrective action and to facilitate decision making by the project manager during 
implementation (McCoy et al., 2005).Monitoring on other hand is the episodic (not continuous as the case with monitoring usually midterm and at end of the project) assessment of state corporation's or completed project to determine its actual impact against the planned impact (strategic goal or objectives for which it is implemented) efficiency, sustainability, effectiveness (McCoy et al., 2005). Monitoring is systematic and independent, and it is an assessment of State Corporation is on completed project including its design, implementation, and results. Monitoring also assesses the relevance, efficiency of application, effectiveness, impact, and sustainability of the project (Uitto, 2004). This study aims at examining the influence of monitoring tools on the performance of projects undertaken state Corporations in Kenya.

\section{LITERATURE REVIEW}

Projects require different monitoring tools depending on the operating context, implementing agency capacity and requirements. It is, therefore, important when preparing monitoring plan to identify methods, procedures, and tools to be used to meet the project's needs (Chaplowe, 2008). There are many tools and techniques used to aid project managers in planning and controlling project activities which include: project selection and risk management tools and techniques; project initiation tools and techniques; project management planning tools and techniques; project management executing tools and techniques; and project management monitoring and control tools and techniques.

The state corporations mainly use two major frameworks: result framework and logical framework (Jaszczolt \& Potkanski, 2010). A framework is an essential guide to monitoring as it explains how the project should work by laying the steps needed to achieve the desired results. A framework, therefore, increases the understanding of the project goals and objective by defining the relationships between factors key to implementation, as well as articulating the internal and external elements that could affect the project's success

While the logical framework identified internationally, is a matrix that makes use of monitoring indicators at each stage of the project as well as identifies possible risks. The logical framework hence shows the conceptual foundation on which the project monitoring system is built (Chaplowe, 2008). It also works well with other monitoring tools (Jaszczolt et al., 2010). Monitoring uses separate tools which are either complementary or substitute to each other while others are either broad or narrow (World Bank, 2012). The monitoring tools include performance indicators, logical framework approach, and theory-based monitoring, set surveys, rapid appraisal methods, and participatory methods, public expenditure tracking surveys, impact 
monitoring, cost-benefit and cost-effectiveness analysis. The selection of these tools, however, depends on the information needed, stakeholders and the cost involved (World Bank, 2008).

Regular methods although costly, have a high degree of reliability and validity and include surveys, participatory observations, and direct measurements among others. Less regular methods which are as well rich in information are subjective and intuitive, hence less precise in conclusion. They include, among others, field visits, and unstructured interviews. Monitoring tools vary with type, sector, and country of application, (KoffiTessio 2002). The Kenyan government when establishing monitoring tools within its state corporation is it should also consider experiences from other organizations in the world (Briceno, 2010). A well prepared and executed Monitoring will contribute to both project outcomes and international standards of doing things (Jha et al., 2010).

\section{METHODOLOGY}

\section{Research Design}

A research design provides a framework for the collection and analysis of data (Bryman \& Bell, 2011). There are many research designs which can be classified into an exploratory, descriptive, correlational or causal but their distinctions are not absolute (Churchill \& Lacobucc, 2005). This research study, therefore, used descriptive research designs.

\section{Target population, sample size, and sampling Technique}

Mugenda and Mugenda (2003) refer to the population as an entire group of individuals and objects having common observable characteristics. Kothari (2004) also concur that population is all items in any field of inquiry or universe. The target population refers to the entire group of people, events or things of interest that the researcher wishes to investigate (Sekaran \& Bougie, 2010). The target population of this study was 187 state corporations in Kenya, which included the commercial state corporation, executive agencies, independent regulatory agencies, research institutions, public universities, tertiary education and training institutions (RoK, 2013).

The choice of the state corporations was justified by the fact that monitoring practices issues are becoming a major concern with the government fighting hard to ensure that there is value for money on services performed. The target respondents will include project managers, finance officers, project team leaders and two end-user key stakeholders who are going to be area leaders affected by the project. The sampling technique that was used in the study is simple random sampling. With simple random sampling, each unit of the population has an equal probability of inclusion in the sample (Bryman \& Bell, 2011). In addition to the purpose of the study 
and population size, three criteria were needed to be specified to determine the appropriate sample size for a simple random sample design: the level of precision, the level of confidence or risk, and the degree of variability in the attribute being measured (Miaoulis \& Michenera, 1976 in Israel, 2013).

The level of precision, sometimes called sampling error, is the range (often expressed in percentage points e.g. \pm 5 ) in which true value of the population is estimated to be. The confidence or risk level is based on the idea that when a population is repeatedly sampled, the average value of the attribute obtained from those samples is equal to the true population value. The degree of variability in the attributes being measured refers to the distribution of attributes in the population. The more heterogeneous a population, the larger the sample size required to obtain a given level of precision. The less variable (more homogenous) a population, the smaller the sample size (Israel, 2013). This is because a given sample size provides proportionately more information for a small population than for a large population. The sample size (n) can be adjusted using the Yamane formula (1967). In this formula, sample size can be calculated at 3\%, 5\%,7\% and $10 \%$ precision (e) levels. Confidence level used is $95 \%$ with degree of variability $(\mathrm{p})$ equivalent to $50 \%(0.5)$.

$$
\begin{aligned}
& \mathrm{n}=\frac{N}{1+N e^{2}} \mathrm{n}=\text { sample size } \\
& \mathrm{N}=\text { target population }(187) \\
& \mathrm{e}=\text { margin error of } 10 \%
\end{aligned}
$$

In the proposed study, the sample size were calculated at precision level of $10 \%(\mathrm{e}=0.1)$.

Sample size in this study is

$$
\begin{gathered}
\mathrm{n}=\frac{187}{1+\left(187 \times 0.1^{2}\right)} \\
\mathrm{n}=\frac{187}{2.87}=65
\end{gathered}
$$

Therefore the sample size was 65 state corporations.

\section{Data Collection Instrument}

The data were taken from reliable sources to ensure the reliability of the study. The research will utilize secondary data collected from Kenya national bureau of statistics, state corporations databases for the period of 2005 to 2015. Dawson (2009) explains secondary research data involves collecting data using information from studies other researchers have done in the area of the subject. Primary data was collected through questionnaires using a nominal scale. Most of the questions were structured on an agreement continuum using a 5-point Likert-type scale. The questionnaire was developed through a review of the literature. 


\section{Pilot Testing, Validity, and Reliability of data collection instruments}

Pilot testing is an important component of the data collection process. A pilot test on a selected sample of respondents was conducted in order to ascertain the validity and reliability of the questionnaire before being administered to the target population. It is usually a small-scale trial run of all the procedures planned for use in the main study. In particular, pilot testing of an instrument administered for research purposes, say a questionnaire, is the standard in social sciences and were employed in the study. Once a questionnaire has been finalized, it should be tried out in the field (Mugenda \& Mugenda, 2003).

One form of pilot testing is pre-testing, which may be repeated several times to refine the questions, the instrument or procedures (Cooper \& Schindler, 2010). According to Cooper and Schindler (2010) and Mugenda \& Mugenda (2003), a sample of at least $10 \%$ of the population is usually acceptable in a pilot study. Therefore, to pre-test the research instrument a sample of 20 state corporations was selected for pilot testing in order to check the validity and reliability of research instruments. Validity is the ability of an instrument to measure what it is designed to measure. It is the correctness or credibility of a description, conclusion, explanation, interpretation, or other sorts of account (Kumar, 2005). According to Kumar (2005), there are two approaches to establishing the validity of a research instrument: logic and statistical evidence.

Validity was established by a logical link between questions and the objectives (Kumar, 2005). To begin with, the phrasing of questions was kept in line with the concept of Zikmund (2010) to increase the validity of the study regarding face validity, content validity and construct validity. Face validity is a subjective means of determining whether the instrument is measuring what it is developed to measure while content validity refers to the representativeness of the items on an instrument as related to the entire domain. Construct validity is the ability of indicators and scales to measure accurately the concept under study (Hair, Black, Babin, \& Anderson, 2010).

Reliability is an assessment of the degree of consistency between multiple measurements of a variable (Hair, Black, Babin, \& Anderson, 2010). Reliability is a measure of the degree to which a research instrument yields consistent results or data after repeated trials (Mugenda \& Mugenda, 2003). Reliability relates to the consistency of the data collected and degree of accuracy in the measurements made using a research instrument. The greater the ability of the instrument to produce consistent results, again and again, or rather the repeatability of the measure the greater its reliability. An item analysis was conducted to determine internal consistency and reliability of each individual item as well as each sub-scale of the data collection instrument in accordance with Kumar (2005). 
Cronbach's Alpha reliability coefficient, $\alpha$, was used for the internal reliability test. The coefficient normally ranges between 0 and 1 although actually, no lower limits exist. The closer $\alpha$ is to 1.0 the greater the internal consistency of the items in the scale. The size of $\alpha$ was determined by both the number of items in the scale and the mean inter-item correlations based upon the formula:

$$
\alpha=\frac{r k}{[1+(k-1) / r]}
$$

where; $\mathrm{k}=$ is the number of items considered and $\mathrm{r}=$ is the mean of interitem correlations.

George \& Mallery (2003) provide the following commonly accepted rules of thumb: $\alpha \geq 0.9-$ Excellent; $0.9>\alpha \geq 0.8$ - Good; $0.8>\alpha \geq 0.7-$ Acceptable; $0.7>\alpha \geq 0.6$ - Questionable; $0.6>\alpha \geq 0.5-$ Poor and $0.5>\alpha-$ Unacceptable. As illustrated in Tables 1 and 2 all the monitoring tools items and project performance items had a Cronbach value of over 0.7.

Table 1: Reliability Analysis for Monitoring Tool

\begin{tabular}{|c|c|c|c|}
\hline & $\begin{array}{l}\text { Corrected } \\
\text { Item-Total } \\
\text { Correlation }\end{array}$ & $\begin{array}{l}\text { Squared } \\
\text { Multiple } \\
\text { Correlation }\end{array}$ & $\begin{array}{l}\text { Cronbach's } \\
\text { Alpha if } \\
\text { Item } \\
\text { Deleted }\end{array}$ \\
\hline $\begin{array}{l}\text { Monitoring tools are well assessed if they are applicable in } \\
\text { organization activities }\end{array}$ & 0.601 & 0.893 & 0.781 \\
\hline $\begin{array}{l}\text { Employees are well trained on Monitoring tools in } \\
\text { organization projects }\end{array}$ & 0.516 & 0.661 & 0.794 \\
\hline $\begin{array}{l}\text { The organization consults widely on the best monitoring } \\
\text { tools to be used }\end{array}$ & 0.253 & 0.702 & 0.833 \\
\hline $\begin{array}{l}\text { The organization uses monitoring tools which are } \\
\text { internationally recognized }\end{array}$ & 0.375 & 0.857 & 0.818 \\
\hline $\begin{array}{l}\text { The organization audits its financial tools in controlling its } \\
\text { project cost }\end{array}$ & 0.756 & 0.813 & 0.749 \\
\hline Metrics are used to check risks in organization & 0.79 & 0.899 & 0.74 \\
\hline $\begin{array}{l}\text { Inspection checklist is used in standardizing organization } \\
\text { monitoring practices }\end{array}$ & 0.578 & 0.877 & 0.783 \\
\hline Cronbach's Alpha & 0.813 & & \\
\hline Cronbach's Alpha Based on Standardized Items & 0.807 & & \\
\hline
\end{tabular}

Table 2: Reliability Analysis of Project Performance

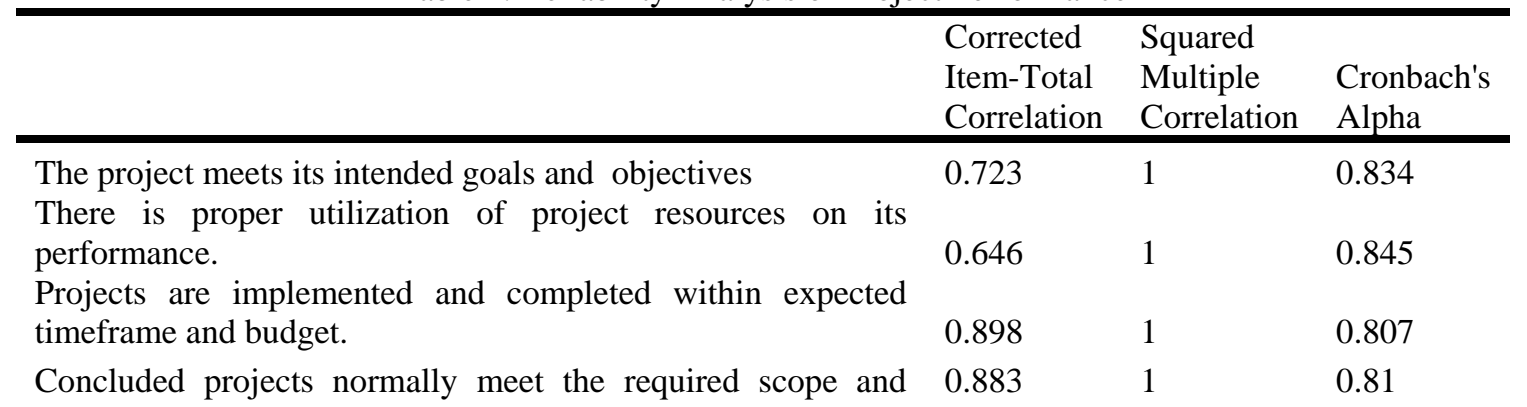


quality projects standard

Monitoring facilitates transparency and accountability of the

of project resources.

0.62

0.991

0.85

The organization gives regular project progress reports on its performance

0.679

0.999

0.84

Most of the project initiated are of good quality

0.074

1

0.909

Cronbach's Alpha

0.865

Cronbach's Alpha Based on Standardized Items

0.862

\section{Statistical Tests}

Statistical tests that were used in the research study include the $t$-Test, ANOVA ( $F$-Test), Shapiro-Wilk test (test for normality) and Durbin-Watson test. Durbin-Watson statistic was obtained to examine the independence of errors. The assumption of independence is given by $D=\frac{\sum_{i=2}^{n}\left(e_{i}-e_{i-1}\right)^{2}}{\sum_{i=2}^{n} e_{i}^{2}}$ where $e_{i}=y_{i}-a-b x_{i}(i=1,2 \ldots, n)$ are residuals. The value $\mathrm{D}$ lies between 0 and 4 . When it is correlated residuals, it approaches 4 . A value of D between 1 and 3 is usually considered to be accepted (Kothari \& Garg, 2014). F-tests were used to test the overall validity of the model or to test if any of the explanatory variables is having a linear relationship with the response variable. Under the normality of residuals, the test statistic $F_{c}$ follows Snedecor's $F$ distribution with (1, n-k-1) degree of freedom.

The null hypothesis was rejected when the computed value is higher than the critical value $F_{\alpha}$. When the variables $X$ and $Y$ are linearly correlated, it is meaningless to fit a linear regression model between them. Therefore, $t$ Test is being used to examine whether there is some significant linear relationship between the independent and dependent variables or not (Kothari \& Garg, 2014). The decision about the null hypothesis in a twotailed test were taken by comparing the computed value and critical value of $t$ distribution. The null hypothesis is rejected at $\alpha \times 100 \%$ level of significance when the computed value and critical value $T_{r}$ is lower than $-t_{\alpha / 2}$ or larger than $t_{\alpha / 2}$. Rejecting a null hypothesis means there is a significant linear relationship between the variables (Kothari \& Garg, 2014).

Many of the statistical procedures including correlation, regression, $t$ tests, and analysis of variance, namely parametric tests, are based on the assumption that the data follow a normal distribution or a Gaussian distribution. The assumption of normality is especially critical when constructing reference intervals for variables and when this assumption does not hold, it is impossible to draw accurate and reliable conclusions about reality (Ghasemi \& Zahediasl, 2012). The normality tests are supplementary to the graphical and numerical assessment of normality. The main tests for the assessment of normality are Kolmogorov-Smirnov (K-S) test, Lilliefors corrected K-S test, Shapiro-Wilk test, Anderson-Daring test, Cramer-von 
Mises test, D'Agostino skewness test, Anscombe-Glynn kurtosis test, D'Agostino-Pearson omnibus test, and the Jarque-Bera test. Among these, K$\mathrm{S}$ is a much-used test (Ghasemi\& Zahediasl, 2012).

However, K-S test has some limitations. The test is highly sensitive to extreme values; the Lilliefors correction renders this test less conservative. According to (Thode, 2002), the K-S test has low power and it should not be seriously considered for testing normality. The study will, therefore, use the Shapiro-Wilk test for testing the normality of data in line with the recommendation of Thode (2002). The Shapiro-Wilk test is based on the correlation between the data and the corresponding normal scores and provides better power than the K-S test even after the Lilliefors correction (Steinskog, 2007; Mendes \& Pala, 2003). Power is the most frequent measure of the value of a test for normality - the ability to detect whether a sample comes from a non-normal distribution (Thode, 2002).

Multicollinearity exists when two or more of the predictors in a regression model are moderately or highly correlated. Unfortunately, when it exists, it can wreak havoc on analysis and thereby limit research conclusions in this study it were detected when the $t$-tests for each of individual slopes are non-significant $(P>0.05)$, but the overall $F$-test for testing all of the slopes are simultaneously 0 is significant $(P<0.05)$; hence relying on variance inflation factor $(V I F)$ quantifies how much the variance is inflated; the variances of the estimated coefficients are inflated when multicollinearity exists. So, the variance inflation factor for the estimated coefficient $b_{k}$ denoted $V I F_{k}$ is just the factor by which the variance is inflated in a model in which $X$ is the only predictor: $y i=\beta 0+\beta k x 1 k+\beta k x 2 k+\beta k x 3 k+\beta k x 4 k+\epsilon i$ it can be shown that the variance of the estimated coefficient $b_{k}$ is: $\operatorname{Var}(b k) \min =\sigma 2 \sum n i=1\left(x i k-x^{-} k\right) 2$ if some of the predictors are correlated with the predictor $X$, then the variance of $b_{k}$ is inflated.

It can be shown that the variance of $b_{k}$ is: $\operatorname{Var}(b k)=\sigma 2 \sum n i=1\left(x i k-x^{-} k\right) 2 \times 11-R 2 k \quad$ Where $R 2 k$ is the $R^{2}$-value obtained by regressing the $k^{\text {th }}$ predictor on the remaining predictors. the greater the linear dependence among the predictor $X$ the larger the $R 2 k$ value; the larger the $R 2 k$ value, the larger the variance of $b_{k}$ by taking the ratio of the two variances.

$\operatorname{Var}(b k) \operatorname{Var}(b k) \min =\left(\sigma 2 \sum\left(x i k-x^{-} k\right) 2 \times 11-R 2 k\right)\left(\sigma 2 \sum(x i k-x-k) 2\right)=11-R 2 k$. Tha $\mathrm{t}$ is $V I F k=11-R 2 k$ where $R 2 k$ is the $R^{2}$-value obtained by regressing the $k^{\text {th }}$ predictor on the remaining predictors. Hence a variance inflation factor exists for each of the $k$ predictors in a multiple regression models by detecting the presence of multicollinearity in this study.

Heteroscedasticity is the circumstance in which the variability of a variable is unequal across the range of values of a second variable that predicts it. In this study heteroscedasticity was minimized or eliminated 
where possible by ensuring that the data used in hypothesis testing is approximately normal and is accurately transformed and that the right functional forms of regression model are selected and variables presented by scatter plot diagrams of the dependent variable (DV) will widen or narrowed as the value of the independent variable (IV) increases.

\section{RESULTS AND DISCUSSION}

\section{Project monitoring tools utilized by State Corporations in Kenya}

The study sought to establish the monitoring tools used by the State corporations in their attempt to meet the projects' needs. Table 3 illustrates the results. Study findings revealed that monitoring tools are well assessed if they are applicable in organization activities (mean $=4.1, \mathrm{SD}=0.88$ ). Indepth assessment of the monitoring tools is of the essence since project managers are able to make use of monitoring tools that assist with ideas through the project strategies and objectives. In such a case, with the use of the preferred monitoring tools, project managers are able to deduce plans that are ideal and most appropriate to implement.

Furthermore, employees are well trained on monitoring tools in organization projects $($ mean $=4.06, \mathrm{SD}=0.93)$. Employee training on monitoring tools equips them with the knowledge on how to select the appropriate tools that conform with the needs of the stakeholders and takes into account the cost and budget of the project. As well, inspection checklist is used in standardizing organization monitoring practices (mean $=4.03, \mathrm{SD}$ $=0.94)$.

In addition, metrics are used to check risks in organization (mean $=$ $3.79, \mathrm{SD}=1.07)$. For instance, the stakeholders take into account the number of times the timely intervention of risk managers resulted in the faster implementation of project plans. Also, the organization consults widely on the best monitoring tools to be used (mean $=3.63, \mathrm{SD}=0.87$ ). Experiences on monitoring tools from other organization in the world are put into consideration so that there is a well prepared and executed monitoring that contributes to project outcomes that are of international standards. Despite consulting widely on the best monitoring tools, there is still doubt if the organization use monitoring tools which are internationally organized (mean $=3.28, \mathrm{SD}=0.97$ ).

Similarly, it has not been fully established if the organization audits its financial tools in controlling its project cost $($ mean $=2.88, \mathrm{SD}=$ 1.01).Generally, the results on monitoring tools summed up to a mean of 3.57, standard deviation 0.8 and Kurtosis -0.1 . 
Std.

Sd d ns a so Mean Deviation Kurtosis

Monitoring tools are well assessed if they are applicable in organization activities

$\begin{array}{lllllllll}\text { Freq. } & 0 & 25 & 41 & 153 & 125 & 4.1 & 0.88 & 0.15 \\ \% & 0 & 7.3 & 11.9 & 44.5 & 36.3 & & & \end{array}$

Employees are well trained on Monitoring tools in organization projects

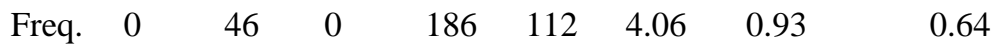

The organization consult widely on the best monitoring tools to be used

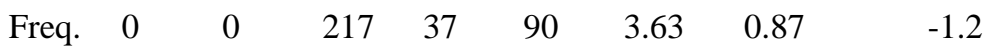

The organization use monitoring tools which are internationally recognized

The organization audits its financial tools in controlling its project cost

Metrics are used to check risks in organization

Inspection checklists are used in standardizing organization monitoring practices

$\% \quad 0 \quad 13.4 \quad 0 \quad 54.1 \quad 32.6$

$\begin{array}{llllllll}\% & 0 & 0 & 63.1 & 10.8 & 26.2 & & -1.2\end{array}$

$\begin{array}{lllllllll}\text { Freq. } & 36 & 0 & 159 & 130 & 19 & 3.28 & 0.97 & 0.9 \\ \% & 10.5 & 0 & 46.2 & 37.8 & 5.5 & & & \end{array}$

$\begin{array}{lllllllll}\begin{array}{l}\text { Freq. } \\ \%\end{array} & 61 & & 218 & 50 & 15 & 2.88 & 1.01 & 0.25 \\ \begin{array}{l}\text { Freq. } \\ \%\end{array} & 0 & 61 & 58 & 117 & 108 & 3.79 & 1.07 & -1.1 \\ & & 17.7 & 16.9 & 34 & 31.4 & & & \\ & & & & & & & & \\ \begin{array}{l}\text { Freq. } \\ \%\end{array} & 0 & 25 & 72 & 113 & 134 & 4.03 & 0.94 & -0.7 \\ & 0 & 7.3 & 20.9 & 32.8 & 39 & & & \\ & & & & & & 3.57 & 0.8 & -0.1\end{array}$

monitoring tools

\section{Project performance of State Corporations in Kenya}

This section of the analysis highlights the results on project performance. Table 4 presents the results. From the results, there was doubt whether most of the projects initiated are of good quality (mean $=3.42, \mathrm{SD}=$ 1.27).It is also uncertain if projects are implemented and completed within expected timeframe and budget (mean $=2.8, \mathrm{SD}=1.45$ ). Similarly, it is undefined if concluded projects normally meet the required scope and quality projects standard (mean $=2.61, \mathrm{SD}=1.41$ ). Furthermore, there is uncertainty as to whether there is proper utilization of project resources on its performance $($ mean $=2.5, \mathrm{SD}=1.54)$. The poor acquisition of the suitable monitoring practices by state corporations' is as a result of the emphasis on physical infrastructure such as computers than on conceptual training. 
On the same note, there is doubt if the project meets its intended goals and objectives (mean $=2.47, \mathrm{SD}=1.72$ ). The implication is that the concerned stakeholders lack sufficient data and metrics to ascertain that the projects have met their intended goals and objectives. However, the respondents denied that monitoring facilitates transparency and accountability of the project resources (mean $=2.29, \mathrm{SD}=1.13$ ). It could be that there is resource misuse despite concerted efforts at monitoring the projects. The respondents also denied that the organization gives regular project progress reports on its performance $($ mean $=2.1, \mathrm{SD}=1.31)$. On the whole, findings on project performance summed up to a mean of 3.64, standard deviation 0.93 and kurtosis -0.6 .

Table 4: Project performance

\begin{tabular}{|c|c|c|c|c|c|c|c|c|c|}
\hline & & $\mathrm{SD}$ & $\mathrm{D}$ & NS & A & $\mathrm{SA}$ & Mean & $\begin{array}{l}\text { Std. } \\
\text { Deviation }\end{array}$ & Kurtosis \\
\hline $\begin{array}{l}\text { The project meet its intended goals } \\
\text { and objectives }\end{array}$ & $\begin{array}{l}\text { Freq. } \\
\%\end{array}$ & $\begin{array}{l}177 \\
51.5\end{array}$ & $\begin{array}{l}19 \\
5.5\end{array}$ & $\begin{array}{l}52 \\
15.1\end{array}$ & $\begin{array}{l}0 \\
0\end{array}$ & $\begin{array}{l}96 \\
27.9\end{array}$ & 2.47 & 1.72 & -1.4 \\
\hline $\begin{array}{l}\text { There is proper utilization of } \\
\text { project resources on its } \\
\text { performance. }\end{array}$ & $\begin{array}{l}\text { Freq. } \\
\%\end{array}$ & $\begin{array}{l}132 \\
38.4\end{array}$ & $\begin{array}{l}0 \\
0\end{array}$ & $\begin{array}{l}64 \\
18.6\end{array}$ & $\begin{array}{l}70 \\
20.3\end{array}$ & $\begin{array}{l}78 \\
22.7\end{array}$ & 2.5 & 1.54 & -1.1 \\
\hline $\begin{array}{l}\text { Projects are implemented and } \\
\text { completed within expected } \\
\text { timeframe and budget }\end{array}$ & $\begin{array}{l}\text { Freq. } \\
\%\end{array}$ & $\begin{array}{l}95 \\
27.6\end{array}$ & $\begin{array}{l}82 \\
23.8\end{array}$ & $\begin{array}{l}0 \\
0\end{array}$ & $\begin{array}{l}132 \\
38.4\end{array}$ & $\begin{array}{l}35 \\
10.2\end{array}$ & 2.8 & 1.45 & -1.6 \\
\hline $\begin{array}{l}\text { Concluded projects normally meet } \\
\text { the required scope and quality } \\
\text { projects standard }\end{array}$ & $\begin{array}{l}\text { Freq. } \\
\%\end{array}$ & $\begin{array}{l}95 \\
27.6\end{array}$ & $\begin{array}{l}82 \\
23.8\end{array}$ & $\begin{array}{l}98 \\
28.5\end{array}$ & $\begin{array}{l}0 \\
0\end{array}$ & $\begin{array}{l}69 \\
20.1\end{array}$ & 2.61 & 1.41 & -0.9 \\
\hline $\begin{array}{l}\text { Monitoring facilitates transparency } \\
\text { and accountability of the of project } \\
\text { resources. }\end{array}$ & $\begin{array}{l}\text { Freq. } \\
\%\end{array}$ & $\begin{array}{l}95 \\
27.6\end{array}$ & $\begin{array}{l}125 \\
36.3\end{array}$ & $\begin{array}{l}70 \\
20.3\end{array}$ & $\begin{array}{l}37 \\
10.8\end{array}$ & $\begin{array}{l}17 \\
4.9\end{array}$ & 2.29 & 1.13 & -0.3 \\
\hline $\begin{array}{l}\text { The organization gives regular } \\
\text { project progress reports on its } \\
\text { performance }\end{array}$ & $\begin{array}{l}\text { Freq. } \\
\%\end{array}$ & $\begin{array}{l}156 \\
45.3\end{array}$ & $\begin{array}{l}101 \\
29.4\end{array}$ & $\begin{array}{l}0 \\
0\end{array}$ & $\begin{array}{l}69 \\
20.1\end{array}$ & $\begin{array}{l}18 \\
5.2\end{array}$ & 2.1 & 1.31 & -0.6 \\
\hline $\begin{array}{l}\text { Most of the project initiated are of } \\
\text { good quality }\end{array}$ & $\begin{array}{l}\text { Freq. } \\
\%\end{array}$ & $\begin{array}{l}19 \\
5.5\end{array}$ & $\begin{array}{l}106 \\
30.8\end{array}$ & $\begin{array}{l}0 \\
0\end{array}$ & $\begin{array}{l}149 \\
43.3\end{array}$ & $\begin{array}{l}70 \\
20.3\end{array}$ & 3.42 & 1.27 & -1.3 \\
\hline project performance & & & & & & & 3.64 & 0.93 & -0.6 \\
\hline
\end{tabular}

\section{Factor Analysis for Monitoring tool}

Table 5 shows that the factor loadings results were above 0.5 . This implies that all the factors were retained for further analysis. All monitoring 
tools items namely, monitoring tools are well assessed if they are applicable in organization activities, employees are well trained on Monitoring tools in organization projects, metrics are used to check risks in organization, inspection checklist is used in standardizing organization monitoring practices, the organization consult widely on the best monitoring tools to be used, the organization use monitoring tools which are internationally recognized and the organization audits its financial tools in controlling its project cost were later used for further analysis. To sum up, the first factor accounted for $46.241 \%$ of the total variance and the second factor accounted for $78.6 \%$ of the total variance. The Kaiser-Meyer-Olkin Measure value (0.585) was above 0.5 hence acceptable. Also, Bartlett's Test was significant.

Table 5: Factor Analysis for Monitoring tool

Component

Component 1

2

Monitoring tools are well assessed if they are applicable in organization activities

Employees are well trained on Monitoring tools in organization projects

Metrics are used to check risks in organization

0.902

Inspection checklist is used in standardizing organization monitoring practices

The organization consults widely on the best monitoring tools to be used

The organization uses monitoring tools which are internationally recognized

The organization audits its financial tools in controlling its project cost

Total Variance Explained: Rotation Sums of Squared Loadings

Total

$\%$ of Variance

Cumulative \%

\section{KMO and Bartlett's Test}

Kaiser-Meyer-Olkin Measure of Sampling Adequacy.

df

Extraction Method: Principal Component Analysis.

Rotation Method: Varimax with Kaiser Normalization.

\section{Factor analysis on Project Performance}

Factor analysis was conducted in order to make sure that the items belong to the same construct (Wibowo 2008). Table 6 illustrates the factor analysis for project performance. As shown in the table, there were no 
exceptions, as all variables scored above the threshold of 0.5 . The criterion for commonality was fulfilled by project performance items notably, the project meets its intended goals and objective, there is proper utilization of project resources on its performance, projects are implemented and completed within expected timeframe and budget, concluded projects normally meet the required scope and quality projects standard, monitoring facilitates transparency and accountability of the of project resources, the organization gives regular project progress reports on its performance and most of the project initiated are of good quality. Additionally, the first factor accounted for $50.596 \%$ of the total variance and the second factor $85.095 \%$ of the total variance.

The KMO Measure is an index for comparing the magnitude of the observed correlation coefficients to the magnitude of the partial correlation coefficients. As shown in Table 6, KMO was greater than 0.5, and Bartlett's Test was significant.

Table 6: Project Performance

\begin{tabular}{lll}
\hline & 1 & 2 \\
\hline The project meets its intended goals and objectives & 0.933 & \\
There is proper utilization of project resources on its performance. & 0.971 \\
Projects are implemented and completed within expected timeframe and & \\
budget. & 0.912 \\
Concluded projects normally meet the required scope and quality projects & & \\
standard & 0.721 & 0.598 \\
Monitoring facilitates transparency and accountability of the of project resources. & 0.707 \\
The organization gives regular project progress reports on its performance & & 0.891 \\
Most of the project initiated are of good quality & & 0.793 \\
Rotation Sums of Squared Loadings & 3.542 & 2.415 \\
Total & 50.596 & 34.5 \\
\% of Variance & 50.596 & 85.095 \\
Cumulative \% & & \\
KMO and Bartlett's Test & 0.253 \\
Kaiser-Meyer-Olkin Measure of Sampling Adequacy. & 5627.555 \\
Bartlett's Test of Sphericity, Approx. Chi-Square & 21 & \\
Df & 0.000 & \\
Sig. & & \\
\hline
\end{tabular}

Extraction Method: Principal Component Analysis.

Rotation Method: Varimax with Kaiser Normalization.

\section{Normality}

Hair et al. (2010), suggested that both the graphical plots and any statistical tests (Shapiro-Wilk or Kolmogorov-Smirnov test) can be used to assess the actual degree of departure from normality. To identify the shape of the distribution, Kolmogorov-Smirnov was used (Shapiro and Wilk,1965) 
which were calculated for each variable. The results from these tests revealed (Table 7) that all the variables were not significant, which meets the assumptions of normality.

Table 7: Normality

\begin{tabular}{lllllll}
\hline & \multicolumn{2}{l}{ Kolmogorov-Smirnova } & \multicolumn{2}{l}{ Shapiro-Wilk } & \\
& Statistic & df & Sig. & Statistic & df & Sig. \\
\hline monitoring tools & 0.296 & 344 & 0.076 & 0.786 & 344 & $.200^{*}$ \\
Project performance & 0.229 & 344 & 0.125 & 0.824 & 344 & $.200^{*}$ \\
\hline
\end{tabular}

a Lilliefors Significance Correction

\section{Homoscedasticity}

The test for homoscedasticity for two metric variables is best examined graphically or through the use of a statistical test. The Levene Statistic for equality of variances was used to test for the assumption of homoscedasticity. Table 8 shows that testing at the 0.05 level of significance; none of the Levene statistics was significant. The assumption of homoscedasticity was not violated.

Table 8: Homoscedasticity

\begin{tabular}{lllll}
\hline & Levene & & & \\
& Statistic & df1 & df2 & Sig. \\
\hline monitoring tools & 2.243 & 1 & 632 & 0.135 \\
Project performance & 1.494 & 1 & 632 & 0.222 \\
\hline
\end{tabular}

\section{Multicollinearity}

Multicollinearity means that two or more of the independent variables are highly correlated and this situation can have damaging effects on the results of multiple regressions. High multicollinearity is signaled when inter-correlation among the independents is above 0.9 (Hair et al., 2006 as cited by Saunders et al. 2009), 0.8 (Garson, 2013), 0.7 (Sekaran and Bougie, 2010), or when high R-squared and significant $F$ tests of the model occur in combination with non-significant t-tests of coefficients. The VIF values were 1.445 which is less than four meaning that there was no multicollinearity.

\section{Correlations}

Correlation coefficients are the statistical method utilized to explore the five variables: project performance, monitoring planning, monitoring tools, monitoring techniques and monitoring practices adoption. The results of the correlation analysis are presented in Table 9. The correlation between monitoring tools and project performance was significant, $\mathrm{r}=0.439, \mathrm{P}<$ 0.01. The results are consistent with findings by Chaplowe, (2008) who found a significant link between monitoring tools and project performance. 
Table 9: Correlations

\begin{tabular}{llll}
\hline & & project performance & monitoring tools \\
\hline project performance & $\begin{array}{l}\text { Pearson Correlation } \\
\text { Sig. (2-tailed) }\end{array}$ & & \\
& & & \\
\multirow{2}{*}{ monitoring tools } & Pearson Correlation & $.439 * *$ & 1 \\
& Sig. (2-tailed) & 0.000 & 0.000 \\
\hline
\end{tabular}

** Significant at 0.01 level

\section{Hypothesis Testing}

The study sought to test the hypothesis that there is a significant relationship between monitoring tools and project performance in Kenyan State Corporations. Nonetheless, the study findings showed that monitoring tools have no significant effect on project performance basing on $\beta_{2}=0.073$ ( $\mathrm{p}$-value $=0.061$ which is more than $\alpha=0.05)$. Furthermore, the effect of monitoring tools was stated by the t-test value $=1.876$ which implies that the standard error associated with the parameter is less than the effect of the parameter.

\section{CONCLUSION}

Monitoring tools have no significant effect on project performance of state corporations in Kenya. It could be that the monitoring tools were not modified to meet the specific needs of Kenya state corporations.Moreover, there is also a possibility that the monitoring tools were unable to map out the needed steps to attain the desired project results.the various mathematical tools were used to see how monitoring tools could affect project performance. These tools conjunctively reinforce the hypothesis developed in the research.

\section{References:}

1. Bryman, A., \& Bell, E. (2011). Business Research Methods (3 ed.). New York, United States: Oxford University Press Inc.

2. Chaplowe, S. G., (2008). Monitoring and evaluation planning module. American Red Cross and Catholic Relief services. Washington, DC and Baltimore, MD.

3. Cooper, D., \& Schindler, P., (2010). Business Research Methods, $12^{\text {th }}$ Edition.Published by McGraw-Hill/Irwin, a business unit of The McGraw-Hill Companies, Inc.

4. Dawson, C. (2009). Introduction to Research Methods. A practical guide for anyone undertaking a research project. How to books Ltd.3 Newtec place, United Kingdom. 
5. Ghasemi, A., \& Zahediasl, S. (2012). Normality Tests for Statistical Analysis: A Guide for Non-Statisticians. International Journal of Endocrinology \& Metabolism, 10(2), 486-489.

6. Israel, G. D. (2013, June). Determining Sample Size. Program Evaluation and Organizational Developments, IFAS, University of Florida, PEOD6.

7. Jaszczolt, K. \&Potkanski, T (2010). Internal project $M \& E$ systems and development of evaluation capacity. The experience of World Bank-funded rural programs.

8. Koffi-Tessio, B. (2002). Efficacy and efficiency of monitoring and evaluation for projects financed by bank group. African development bank group.

9. Kothari, C. R. (2004). Research Methodology: Methods and Techniques. New Delhi: New Age International Publishers.

10. Kothari, C. R., \& Garg, G. (2014). Research Methods: Methods and Techniques. New Delhi: New Age International (P) Limited.

11. McCoy, K.L., Ngari, P. N., \&Krumpe, E., (2005). Building Monitoring, Evaluation and Reporting Systems for HIV/AIDS Programs.Pact.The United States of America.

12. Mendes, M., \& Pala, A. (2003). Type I Error Rate and Power of Three Normality Tests. Pakistan Journal of Information and Technology, 2(2), 135-139.

13. Mugenda .\&Mugenda, (2003). Research methods; quantitative and qualitative approaches. Africa Center for Technology (ACTS), Nairobi Kenya.

14. The Republic Of Kenya, (2013), Economic Survey Nairobi Kenya: Government Printers.

15. Saunders, M., Lewis, P., \&Thornhill, A., (2009).Research Methods for Business Students, Financial Times/Prentice Hall, (4th Edition), UK, p. 105-108, 134.

16. Sekaran, U., \&Bougie, R. (2010). Research Methods for Business: A Skill Building Approach (5th ed.). West Sussex, UK: John Wiley \& Sons Ltd.

17. Shapiro, S. S., \& Wilk, M. B. (1965). An Analysis of Variance Test for Normality (Complete Samples). Biometrika, 52(3/4), 591-611.

18. Steinskog, D. J. (2007). A Cautionary Note on the use of the Kolmogorov-Smirnov test for normality. American Meteor Soc, 135, 1151-1157.

19. Thode, H. J. (2002). Testing for Normality. New York: Marcel Dekker 
20. Uitto, J. A. (2004).Multi-country cooperation around shared waters: Role of Monitoring and Evaluation. Global environmental change, 14(1): 5-14.

21. World Bank. (2008).Infrastructure Assessment, Finance, Private Sector, and Infrastructure Group, Middle East \& North Africa, December 2008.

22. World Bank. (2012).Monitoring and Evaluation: Some tools, methods, and approaches. The World Bank. Washington, D.C.

23. Yamane, T. (1967).Statistics: An Introductory Analysis, $2^{\text {nd }}$ edition, New York: Harper and Row 